\title{
Isolation and Diagnosis of Candida albicans Yeast From Patients Infected With Oral Candidiasis in Mosul City and Study its Activity in Production of Phospholipase and Hemolycin
}

\author{
Rafea Qasim Altaee $^{1 *}$; Rafia Qader Alzubaidy ${ }^{2}$ \\ ${ }^{1,2}$ Department of Biology, College of Education for Pure Science, University of Mosul, Mosul, Iraq \\ Email: ${ }^{1 *}$ dr.rafeaqm@uomosul.edu.iq, ${ }^{2}$ rafiajarjes@ yahoo.com
}

(Received September 24, 2019; Accepted November 21, 2019; Available online June 01, 2020)

DOI: 10.33899/edusj.2019.126122.1020, ( ) 2020, College of Education for Pure Science, University of Mosul.

This is an open access article under the CC BY 4.0 license (http://creativecommons.org/licenses/by/4.0/).

\begin{abstract}
In this study, 63 oral swabs were collected . Thirty six yeast isolates were obtained (57.14\%) grown on sabouraud dextrose agar medium (SDA). Symbols were given to isolates from RA1 to RA36 in order to differentiate them. The isolates were identified by growth on HiCrome Candida differential agar M1297A and identification by Vitek 2 Compact system.

The identification results showed 5 species of the isolated yeasts belonging to the genus Candida, 29 isolates belonging to the species C. albicans (80.55\%) and one species from C. famata, C. glabrata, C. kefyr and C. lusitaniae (2.77\% for each species). Moreover one isolate was obtained from each of the following yeasts: Saccharomyces serevisiae, Malassezia furfur and Rhodotorula glutinis $(2.77 \%$ for each one).

This study included the evaluation of two virulence factors for all C. albicans isolates, phospholipase enzyme production on egg yolk agar and hemolytic activity on sugar-enriched sheep blood agar.
\end{abstract}

.Phospholipase production test showed differences in phospholipase production among the isolates , twenty three isolates (79.31\%) were producers and precipitation zone (Opaque zone) was observed around the grown colonies with different $\mathrm{Pz}$ values and the isolate RA13 exhibited highest activity $(\mathrm{Pz}$ value $=0.53)$.

The results showed also that all isolates were producers of hemolysin with different hemolytic indexes $(\mathrm{Hi})$. Isolate RA7 represented the highest one in activity $(\mathrm{Hi}=2.16)$. Hemolysis of all isolates involved beta hemolysis.

Keywords : Candida albicans, Oral Candidiasis, Phospholipase, Hemolycin 


\title{
من المرضى المصابين بداء المبيضات الفووي في Candida albicans عزل وتشخيص خميرة الـ مدينة الموصل ودراسة فعاليتها في إنتاج إنزيم الفوسفولايبيز والهيمولايسين
}

\author{
رافـع قاسـم محمد الطـائي 1" و رافعـة قادر جرجيس الزبيدي2 \\ قسم علوم الحياة, كلية التربية للعلوم الصرفة, جامعة الموصل, الموصل, العراق
}

الخلاصة

تم فى هذه الدراسة جمع 63 مسحة فموية ، وتم الحصول على 36 عزلة خميرية من المجموع الكلى للمرضى أى بنسبة \% 57.14 ، اعطى لهذه العزلات رموز من RA1-RA36 من اجل التمييز بينها. تم تثخيص العزلات بقدرتها على النمو على الوسط التفريقى HiCrome Candida differential agar M1297A والتشخيص بنظام Vitek 2 Compact ـ أظهرت نتائج التشخيص 5 انواع من الخمائر وهى تعود للجنس Candida وأن 29 عزلة تعود للنوع C. albicans أى بنسبة 80.55\% في حين تم الحصول على عزلة واحدة من كل من C. famata و C. glabrata الخمائر Malassezia furfur و Saccharomyces cerevisiae وجرى دراسة عاملى الضراوة لعزلات الـ C. albicans وهما فعالية العزلات فى إنتاج انزيم الفوسفولايبيز على وسط مح البيض الصلب وفعالية العزلات فى تحليل الدم على وسط دم الأغنام الصلب الغنى بالسكر وأظهرت النتائج أن هنـاك

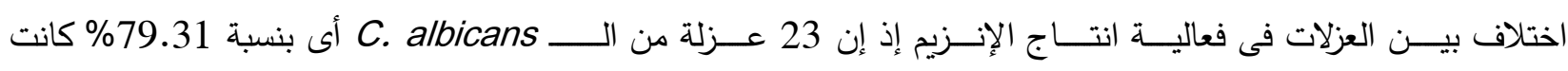
منتجة للانزيم ، وكانت العـزلات المنتجة متفاوتــة فيــــــــــا فى معـدلات الانتاج وقد أظهرت العزلة RA13 اعلى انتاجية اذ بلغت قيمة Pz D 20.53.

أظهرت النتائج أن جميع العزلات كانت منتجة للهيمولايسين ومحللة للدم وبدلائل تحليل متفاوتة ، وكانت جميعها تمتلك فعالية تحليل من نوع بيتا وأظهرت العزلة RA7 اعلى فعالية اذ بلغ قيمة دليل التحليل 2.16 ـ الكلمات المفتاحية : Candida albicans ، داء المبيضات ، انزيم الفوسفولايبيز ، الهيمولايسين المقدمـة

إن داء المبيضـات Candidiasis الذي يطلق عليه أيضـاً Candidosis او Moniliasis (1) إصـابة انتهازية سطحية

تنشأ بسبب عوامل موضعية أو جهازية ويشار إليه بأنه إصابة خميرية أو سلاق Thrush تسببه الخميرة Candida C C C C C أما داء المبيضـات الفموي Oral candidiasis فهو إصـابة انتهازية موضعية شائعة للغشـاء المخاطي الفموي وقابلة Cellular immune deficiency للعلاج ، ويحدث عند الأطفال والمسنين والأثخاص الذين لديهم نقص في المناعة الخلوية 
وتحدث أعراض الإصـابة بشكل لويحات بيضـاء White plaques على الغشـاء المخاطي الفموي والحنك واللسـان او البلعوم الفموي (3) وهذا الداء تسببه خميرة C. albicans (4) لا تسبب خميرة Candida في الحالة الطبيعية المرض لكنها تتشط عند تثبيط الجهاز المناعي أو حصول اختـــلال في تــــوازن النبيت المجهري الطبيعي فان بإمكان الـ C. albicans أن تتحول الى كائن ممرض ، إذ تتمو بشكل مفرط مؤدية الى حدوث اصابه في الاطفال الرضع ومرضى السكري ومرضى العلاج الجراحي ومرضى الإيدز (5). تمتلك خميرة Candida عوامل ضـــراوة واسـتراتيجيات نوعية تســاعدها على التمركز وإحداث المرض والتغلب على الوســائل الدفاعية للعائل ، فهي باسـتطاعتها النمو بأشـكال مظهرية متنوعة تتدرج ما بين خميرة أحادية الخلية متبرعمة (البوغ

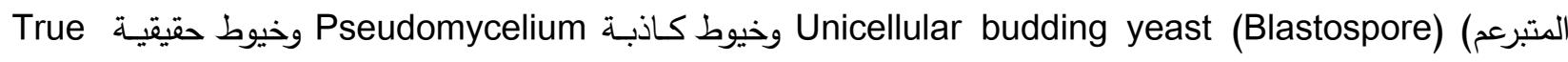
hyphae Phagocyte cells ، وهنالك عوامل اخرى لها علاقة بالضــراوة مثل انتاج بروتين الهيمولايسـين Hemolysin وتكوين أنبوب الإنبات وإنتاج الســموم وإنتاج انزيمات مثل الفوسـفولايبيز Phospholipase والبروتينيز Proteinase والالتصــاق بالخلايا الظهارية والحفاظ على سلامة جدارها الخلوي وتجنب الاستجابة المناعية للعائل (6).

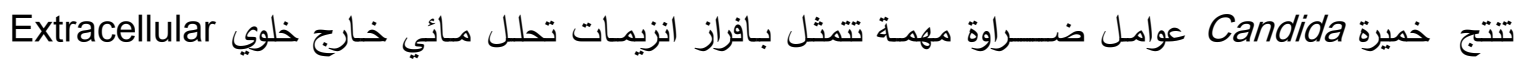
hydrolytic enzymes وهي من عوامل الضــــراوة المهـة لهذه الخميرة (7) ـ ونظراً لان اغثــــــة خلايا العائل تتكون من بروتينات ودهون فانها تكون هدفا لهذه الانزيمات وتصـنف هذه الانزيمات الى نوعين رئيسـين (8) انزيم اسـبارتيل بروتينيز و و مجموعة انزيمات الفوسفولايبيز ويضم الاخير مجموعة من الانزيمات والتي تشترك في قدرتها على التحليل المائي لواحد أو أكثر

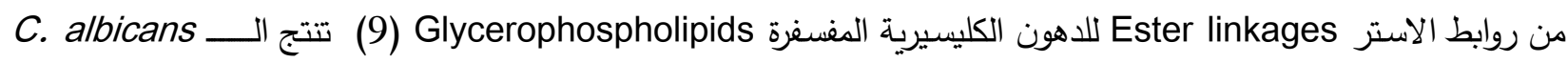
اربعة انواع من هذا الانزيم هي A و B و C و D و صنفت استتاداً على نوع رابطة الاستر التي تحللها (10) • تختلف كمية انتاج انزيم الفوسفولايبيز من قبل الـــ C. albicans باختلاف عزلات الخميرة وكذلك بحسب موقع الإصابة ، إذ ان العزلات المسببة لاصابات مجرى الدم تنتج كميات اكبر من الانزيم مقارنة مع عزلات من الجروح والادرار (8). أما بروتين الهيمولايسين فهو أحد عوامل الضراوة الذي يؤدي دورا في امراضية الــCandida (11) أذ يمكن الكائن الممرض من ان يبقى حيا ويثبت الاصــابة ضــن العائل (12)، و يمكنه من الحصـول على الحديد الضـروري للنمو ويسـل عملية اجتياح الثكل الخيطي عند الاصدابة بداء المبيضات المنتشر Disseminated candidiasis (13) والذي يلعب دوراً

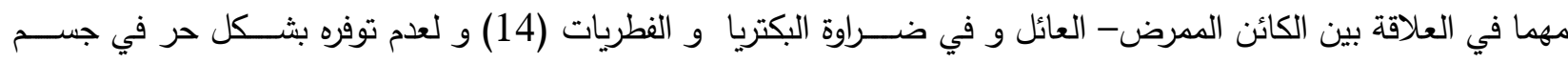
الانســــان لذلك فان معظم الممرضــــات تكتــــب الحديد بثــــل غير مباشــــر من خلال المركبات الحاوية على الحديد والمتوفرة مثل الهيموغلوبين Hemoglobin يمتلك الكائن الممرض آليات لتحطيم جزيئة الهيم Heme واســــتخلاص عنصر

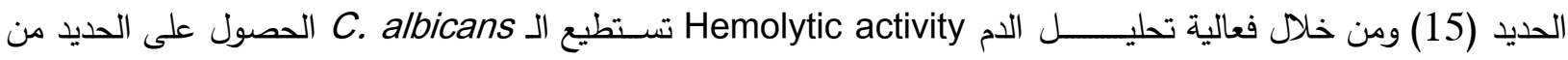
جزيئة الهيموغلوبين المتحرة من كرية الدم الحمراء المنحلة وبالتالي تحافظ على قدرتها على النمو في مصل الإنسان (16) . 
نظرا لما ذكر أعلاه ولأهمية خميرة الـ C. albicans فإننا نهدف من خلال هذه الدراسة الى : 1- عزل خميرة الـ C. albicans من الاصابات الفهوية وتثخيصها بطرائق حديثة ودقيقة. 2- 20 - دراسة بعض عوامل ضراوتها.

المــواد وطرائـــق العمــــلـ

1- المحلول الخزين للمضاد البكتيري ستربتومايسين سلفيت Streptomycin sulfate تم الحصـول على المضــاد بثـكله التجاري وعلى شـكل مسـحوق وتمت اذابة 1 غم منه في 100 مليلتر من الماء المقطر المعقم ـ للحصــــل على محلول خزين بتركيز 10000 مايكروغرام / مليلتر من الماء المقطر وحفظ المحلول الخزين عند درجة

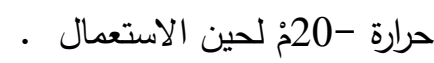

\section{2}

اسـتخدم بيض المائدة للحصــول على مح البيض Egg yolk اذ وضــع في انابيب اختبار معقمة ذات اغطية محكمة ، وضــــت الانابيب في جهاز طرد مركزي HERMLE , Labnet , U.S.A.) Centrifuge عند قوة جاذبية ارضـــية 500 Gravitational force حجمه الاصـلي ( الجزء الطافي مع الراسـب ) بالماء المقطر المعقم ـ استعمل هذا المستحلب مباشـرة في تحضـير وسط مح البيض الصلب (17).

\section{3east cell suspension تحضير عالق خلايا الخميرة}

لتحضير العالق لقح الوسط Sabouraud's dextrose agar medium (SDA) بعزلات الخمائر بطريقة التخطيط Loop Streaking ، حضنت الاطباق في درجة حرارة 37مٌ لفترة 18-24 سـاعة ثم أخذ جزء من اللقاح النامي بواسطة ناقل ووضـع في قنينة زجاجية صغيرة معقة تحوي على 5 مليلتر من المحلول الملحي الوظيفي المعقم ـ مزج العالق جيداً وتم ضبط

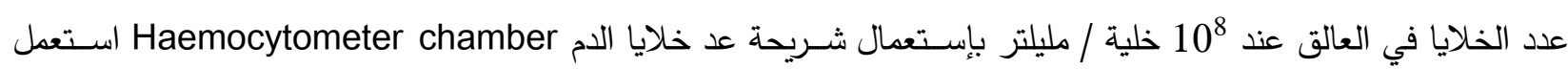
العالق بصورة آنية في اختبار تحلل الدم وفي قياس الفعالية في إنتاج انزيم الفوسفولايبيز .

$$
\text { 4- الاوساط الزرعية }
$$

Sabouraud's dextrose agar medium (SDA) أ- وسط سابرود دكستروز الصلب

حضر الوسط حسب تعليمات الثركة المجهزة (LabM, U.K.) باذابة 62 غم من مسحوق الوسط في لتر من الماء المقطر ثم عقم بجهاز المؤصدة . 


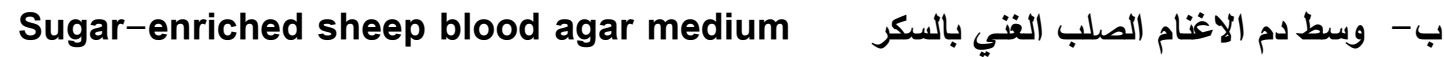

حضر الوسط حسب طريقة Luo واخرين (18) باضـافة 3\% من الكلوكوز الى 1 لتر من وسط SDA وضبط الاس

الهيدروجيني عند 5.6 土 0.2 وبعد التعقيم بجهاز المؤصدة ترك ليبرد الى 45-50مُ ثم اضيف اليه (وفي ظروف معقمة) 7 مليلتر من دم الاغنام الطازج Fresh sheep blood (بيت الحيوانات / كلية الطب البيطري / جامعة الموصــل لكل 100 مليلتر من الوسط SDA الحاوي على الكلوكوز، و مزج جيداً و وزع في اطباق بتري معقدة وترك ليتصلب واستعمل هذا الوسط في اختبار تحلل الدم Hemolysis test

\section{Egg yolk agar medium}

ج - وسط مح البيض الصلب

حضـر الوســ حسـب طريقة Price واخرين (17) بإضــافة 1 مولاري (58.44 غرام) من كلوريد الصـوديوم NaCl و 0.005 مولاري (0.55 غرام) من كلوريد الكالسـيوم CaCl 2 الى 1 لتر من الوســ الغذائي SDA المحضـر كما في الفقرة أ وضـبط الأس الهيدروجيني للوسط عند 4.3 وعقم بالموصـدة ثم ترك الوسـ ليبرد الى درجة حرارة 45-50م ثم أضـيف إليه (وفي ظروف معقدة) مستحلب مح البيض والمحضـر كما في الفقرة 1 بمقدار 8\% (حجم/حجم) مزج و وزع في اطباق بتري واستعمل هذا الوسط لقياس فعالية العزلات في انتاج انزيم الفوسفولايبيز • 5 - 5مع العينات

تم الحصول على العزلات الفطرية من المرضى المصـابين بداء المبيضـات الفوي المراجعين او الراقدين في مستثفى ابن سينا التعليمي ومستثفى ابن الاثير التعليمي ومستشفى السلام العام والمستثفى الجامعي التعليمي / قسم صناعة الاسنان ، من خلال أخذ مسحات فموية بواسطة ممسحات قطنية معقدة Sterile cotton swabs ومررت فوق منطقة الإصابة وتم تدويرها بلطف مع مراعاة عدم لمس الأجزاء غير المصابة لتفادي التداخل مع النبيت الطبيعي Normal flora للفم . جمعت 63 مســحة خلال شـهرين ( من 15/ 3 ولغاية 15/ 5/ 2010 ) ومن اعمار مختلفة تراوحت بين 9 ايام - 80 و سـنة ومن كلا الجنسين وكان المرضسى يعانون من حالات مرضسية مختلفة. كانت نسبة الذكور من عدد المرضسى 39.68

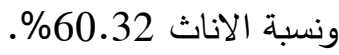
6 - زرع العينات نقلت المسـحات الفموية Swabs الى المختبر مباشـرة وزرعت على الوسط الغذائي SDA الحاوي على المضـاد البكتيري Streptomycin sulfate بتركيز 100 مايكروغرام / مليلتر من الوسـط ـ حضـنت الاطباق في درجة حرارة 37مْ لفترة 2-7

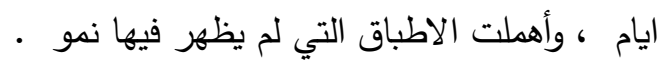


7- التشخيص بالوسط التفريقي الصلب HiCrome Candida differential agar M1297A

تم الحصول على الوسط بشكل جاهز من شركة (HiMedia, India) و حضر الوسط حسب تعليمات الشركة المجزة.

Vitek 2 Compact اختبار تشخيص العزلات بنظام

أجري هذا الاختبار في مختبر الصــحة العامة في محافظة اربيل ، بإسـتعمال نظام التشـخيص Vitek 2 Compact

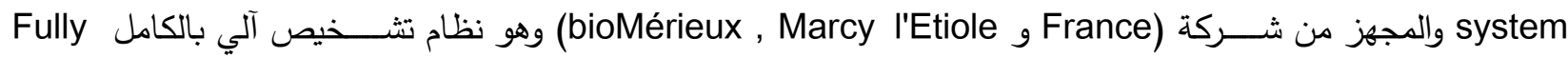
automated ان تشخيص الخمائر بهذا النظام يستند وبشكل رئيس على نظام التفاعل الكيموحيوي (20) .

Phospholipase production activity اختبار فعالية انتاج انزيم الفوسفولايبيز

أجري الاختبار حســبـ طريقـة Price واخرين (17) والتي تعرف بطريقـة الطبق Plate method ، إذ تم نقل 10

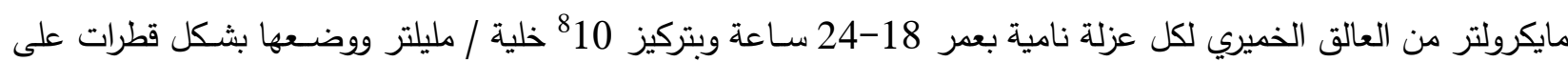
سطح وسط مح البيض الصلب وتركت لتجف عند درجة حرارة المختبر ، ثم حضنت الاطباق في درجة 37خ ولفترة 5 ايام . إن منطقة الترسـيب Precipitation zone (Pz) (المعتمة) والتي تظهر بثـكل منطقة بيضــاء كثيفة حول المسـتعمرات تمثل النتيجة الموجبة في إنتاج انزيم الفوسـفولايبيز • إن المعدل الناتج من تقسـيم قطر المسـتعمرة على مجموع قطر المسـتعمرة زائدا قطر منطقة الترسيب والذي يرمز لله PZ يمثل وحدة قياس فعالية إنتاج انزيم الفوسفولايبيز •

قطر المستعمرة

قطر المستعمرة + قطر منطقة التزسيب

Hemolysis ب اختبار تحلل الام

Plate assay تم اختبار فعالية العزلات في تحليل الدم وإنتاج بروتين الهيمولايســين باســـعمال طريقة تحلل الطبق Luo وآخرون (18) والتي وصفئ والمــورة عن الطريقــة التي وصفها Manns وآخرون (21) ، تضمنت الطريقة نقل 10 مايكرولتر من العالق الخميري لكل عزلة نامية بعمر 18-24 ساعة وبتركيز 108 خلية/ مليلتر ووضعها بثكل قطرات لتكون بقعا Spots على سطح وسط دم الأغنام الصلب الغني بالسكر ثم تركت لتجف عند درجة حرارة المختبر ثم حضنت في درجة 37؛ ولفترة 48 ساعة وبوجود 5\% من غاز Candle jar واستخدمت جرة الثمعة CO عند التحضين في هذه التجربة. يستلدل على النتيجة الموجبة بظهور هالة نصف شفافة Translucent halo و / أو سوداء مخضرة Greenish-black حول المستعمرة والتي يمكن رؤيتها بإستعمال ضوء نفاذ Transmitted light. 
استخدمت المسطرة في قياس اقطار المستعمرات النامية ، والمعدل الناتج من تقسيم مجموع قطر المستعمرة زائدا الهالة على قطر المستعمرة وحدها يعطي دليلاً للتحليل Hemolytic index (Hi) وهذا المعدل يساوي او اكبر من 1.

$$
\text { قطر (المستعمرة + الهالـة) }
$$

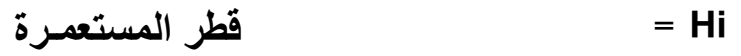

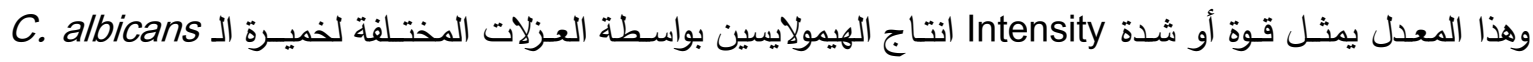

النتائـج والمناقشــة

$$
1
$$

ظهرت العزلات النامية على وسط سـابرود دكسـتروز الصـلب SDA في العزل الأولي بثكل مستعمرات بيضــاء الى كـ كريمية Creamy اللون وناعمة Smooth وزبدية القوام Butyrous وذات شكل محدب Convex وهذه الصفات هي مطابقة لصفات الخمائر التي وصفها Kurtzman و Fell (23). ويستعمل الوسط SDA بشكل واسع لعزل أنواع الخمائر المختلفة باعتباره وسط نموذجي لعزل الـ Candida يسمح بنموها ويكبح نمو أنواع كثيرة من البكتريا الفموية وذلك لانخفاض الأس الهيدروجيني لهذا الوسط كما أن إضـافة المضـاد البكتيري يزيد من انتقائيته (24) من 2- 2 - تثخيص العزلات بالوسط التفريقـي

\section{HiCrome Candida differential agar M1297A}

أظهرت نتائج هذا الاختبار أن جميع العزلات ( 36 عزلة ) استطاعت النمو بصورة جيدة على الوسط التقريقي 100\%

، ظهرت المسـتعرات النامية بألوان مختلفة بعضـها كان مطابقاً والبعض الآخر يختلف عن تعليمات الثـركة المجهزة للوسـط التفريقي HiCrome Candida differential agar التي تبين ان هذا الوســــ يميز بين أربعة أنواع من الخمائر التابعة

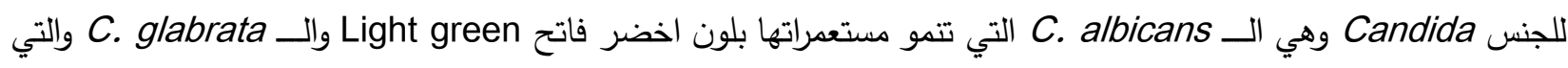
تتمو بلون كريدي الى أبيض والــ C. krusei والتي تتمو بلون ارجواني ، زغبي C. tropicalis والــ Purple, fuzzy التي تتمو بلون أزرق الى ارجواني Blue to purple. وقد أظهرت نتائج هذا الاختبار كما هو مبين في الجدول (1) إن 30 عزلة كانت موجبة لهذا الاختبار أي بنســبة 83.33\% ومنها 29 عزلة (80.55\%) شـخصـت على أنها الخميرة C. albicans إذ ظهرت مستعمراتها بلون أخضـر فاتح ذات أشكال ملساء محدبة ، وعـزلة واحدة ونسبتها 2.77\% شـخصت على أنهـا الخميـرة C. glabrata وظهرت مستعمراتها 
بلون أبيض ، اما العزلات الست الباقية التي نسبتها 16.67 \% فكانت سـالبة لهذا الاختبار وظهرت مستعمراتها بلون وردي فاتح Light pink ولم نتمكن من تشخيصها ، لأن هذا اللون غير موجود ضمن تعليمات الشركة المجهة .

HiCrome Candida differential agar M1297A الجدول (1) : ألوان المستعمرات النامية على الوسط التفريقي

\begin{tabular}{|c|c|c|c|}
\hline نوع العزلة & لون المستعمرات النامية على & العدد الع & رمز العزلة \\
\hline Candida albicans & اخضر فاتح & 29 & $\begin{array}{c}\text { RA16، RA14-RA4، RA1 } \\
\text { ‘RA19، RA17، } \\
\text { ، RA27-RA21 } \\
\text { RA36، RA34-RA29 }\end{array}$ \\
\hline Candida glabrata & ابيض ابي & 1 & RA3 \\
\hline غير مشخصة & وردي فاتح & 6 & $\begin{array}{c}\text { RA20 ،RA18، RA15، RA2 } \\
\text { RA35، RA28، }\end{array}$ \\
\hline
\end{tabular}

Vitek 2 Compact 3

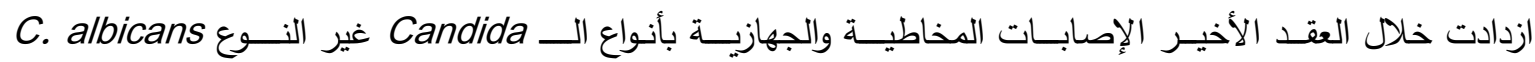
وأن الاصــابات بهذه الأنواع أصــبح لها تأثير مباشـر في العلاج، لذلك فإن التثــخيص على مسـتوى النوع له دور في اختيار المضاد الفطري المناسب مما يقلل من نسبة الإمراضية والوفيات بين المرضى المصابين بهذه الانواع من الاصابات (25). ومن أجل ذلك اســتخدم في هذه الدراســة نظام التثــخيص Vitek 2 Compact الذي يمتاز بالدقة والســرعة في تثـخيص العزلات الى مستوى النوع (19) وقد أظهرت النتائج قدرة هذا النظام على تشخيص جميع عزلات الخمائر قيد الدراسـة أي بنسـبة 100\% وقد ظهرت الخميرة C. albicans بنسـبة 77.77\% وبواقع 28 عزلة في حين كانت الثمان عزلات الباقية تعود لأنواع أخرى من الخمائر والتي ظهرت كل منها بواقع عزلة واحدة أي بنسبة 2.77\% لكل منها، كماهو مبين في الجدول (2) ـ كما أظهرت نتائج الاختبار نسبة الاحتمالية Probability في تثـخيص العزلات إذ يعمل نظام التثـخيص على المقارنة ما بين نتائج التفاعلات الكيموحيوية مع المعلومات المتوفرة في قاعدة بيانات النظام ثم تحســب النســـبة المئوية لاحتمالية التثخيص لكل عزلة والتي تراوحت بين 87 الى 99\% كما هو موضح في الجدول (2). 
وقد اختلفت نتائج هذا الاختبار في تثخيص الـــ albicans مع نتائج اختبار النمو على الوسط التثريقي إذ ظهرت الـ C. albicans في هذا الاختبار بواقع 28 عزلة بالدقارنة مع نتائج اختبار الندو على الوســ التقريقي التي ظهرت فيها هذه

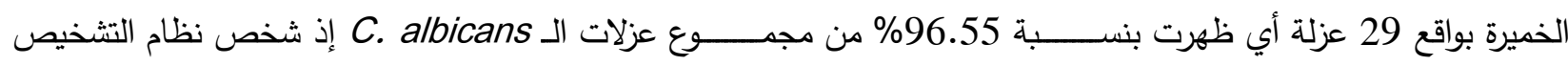
على RA16 أنها الخميرة Cryptococcus neoformans وبذلك كانت نســـبـة التشــــيص الخاطئ Vitek 2 Misidentification التشـــيص الصــحيح تتراوح ما بين 84 الى 99\% وهذا يعزى الى الاختلافات الواضــــة بين الدراســات فيما يتعلق بالأنواع الدروسة وعدد العزلات قيد الاختبار، وكذلك الاختلافات في الموقع الجغرافي لإجراء الدراسة (26) .

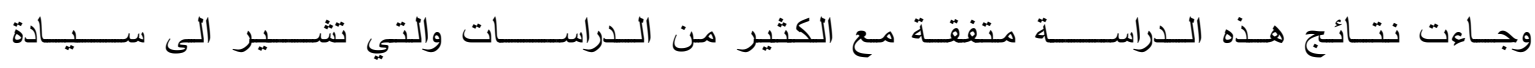
الـــ albicans . في إصابات داء المبيضات ، إذ تُعد من اكثر انواع الخمائر التي تعزل بصورة متكررة من التجويف الفموي (27) ، فهي مسئولة عن 80\% من إصـابات داء المبيضــات و أن تثـخيص الـــCandida على مسـتوى النوع لله أهمية لاختلاف أنواع هذه الخميرة فيما بينها بثكل واسـع من حيث قدرتها على إحداث الإصـابة وكذلك حساسيتها للمضـادات الفطرية 
Vitek 2 Compact الجدول (2): نتائج تشخيص العزلات الخميربة قيد الاراسة بنظام

\begin{tabular}{|c|c|c|}
\hline الاحتمالية (\%) & نوع الخميرة & رمز العزلة \\
\hline 87 & Candida albicans & RA1 \\
\hline 89 & Candida famata & RA2 \\
\hline 99 & Candida glabrata & RA3 \\
\hline 97 & Candida albicnas & RA4 \\
\hline 99 & Candida albicans & RA5 \\
\hline 99 & Candida albicans & RA6 \\
\hline 99 & Candida albicans & RA7 \\
\hline 99 & Candida albicans & RA8 \\
\hline 97 & Candida albicans & RA9 \\
\hline 95 & Candida albicans & RA10 \\
\hline 98 & Candida albicans & RA11 \\
\hline 99 & Candida albicans & RA12 \\
\hline 98 & Candida albicans & RA13 \\
\hline 98 & Candida albicans & RA14 \\
\hline 94 & Candida kefyr & RA15 \\
\hline 87 & Cryptococcus neoformans & RA16 \\
\hline 99 & Candida albicans & RA17 \\
\hline 93 & Candida lusitaniae & RA18 \\
\hline 95 & Candida albicans & RA19 \\
\hline 98 & Saccharomyces cerevisiae & RA20 \\
\hline 99 & Candida albicans & RA21 \\
\hline 99 & Candida albicans & RA22 \\
\hline 94 & Candida albicans & RA23 \\
\hline 99 & Candida albicans & RA24 \\
\hline 99 & Candida albicans & RA25 \\
\hline 98 & Candida albicans & RA26 \\
\hline 99 & Candida albicans & RA27 \\
\hline 87 & Malassezia furfur & RA28 \\
\hline 99 & Candida albicans & RA29 \\
\hline 91 & Candida albicans & RA30 \\
\hline 95 & Candida albicans & RA31 \\
\hline 92 & Candida albicans & RA32 \\
\hline 98 & Candida albicans & RA33 \\
\hline 94 & Candida albicans & RA34 \\
\hline 87 & Rhodotorula glutinis & RA35 \\
\hline 98 & Candida albicans & RA36 \\
\hline
\end{tabular}


4 - فعالية عزلات الـ C. albicans في انتاج انزيم الفوسفولايبيز

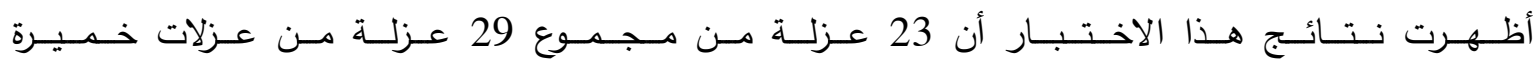

الـــ albicans كانت موجبة لهذا الاختبار أي بنسبة 79.31\% إذ أظهرت فعالية في انتاج انزيم الفوسفولايبيز من خلال ظهور منطقة كثيفة بيضـاء هي منطقة الترسـيب حول المسـتعمرات النامية على وســـــح البيض الصــلب، وتظهر منطقة الترسيب نتيجة تكوين معقد الكالسيوم Calcium complex مع الأحماض الدهنية المتحررة من الدهون المفسفرة الموجودة في مح البيض بفعل تاثير انزيم الفوســفولايبيز (17) • من خلال الجدول (3) نلاحظ أن هناك تفاوتاً بين العزلات في فعالية انتاج الانزيم من خلال التفاوت في أقطار مناطق الترسيب، وبالتالي تبايناً في قيم Pz والتي تراوحت من 0.53 الى 0.80 ، وبحسب التصــنيف الذي وضـــــ Price واخرون (17) في تقييم فعالية إنتاج الإنزيم فإن نتائج دراســتـا أظهرت أن 10 من العزلات

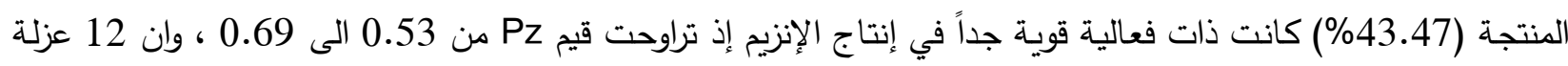
(52.17\%) كانت ذات فعالية قوية نسـبياً إذ تراوحت قيم Pz من 0.72 الى 0.77 اما العزلة RA19 (4.34\%) فقد أظهرت فعالية معتدلة إذ كانت قيمة Pz لها 0.80.

ومن خلال إجراء التحليل الاحصـائي باختبار دنكن المتعدد المدى عند مستوى احتمال 1\% نلاحظ أن هناك تفاوتاً في قدرة العزلات على إنتاج الانزيم ، وقد أظهرت العزلة RA13 اعلى انتاجية من بين جميع العزلات المنتجة إذ اخذت قيمة الاتتاج

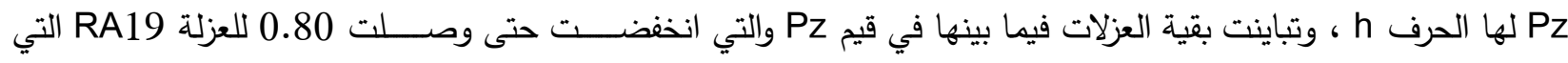
أظهرت أقل إنتاجية بالمقارنة مع العزلات المنتجة الأخرى وأخذت قيمة Pz لها الحرف a إحصائياً. استعملنا في دراستنا طريقة الطبق التي اقترحها Price واخرون (17) في تقييم فعالية انتاج انزيم الفوسفولايبيز وهي طريقة سهلة وسريعة في تحديد وقياس فعالية إنتاج انزيم الفوسفولايبيز في الـ C. albicans (28).

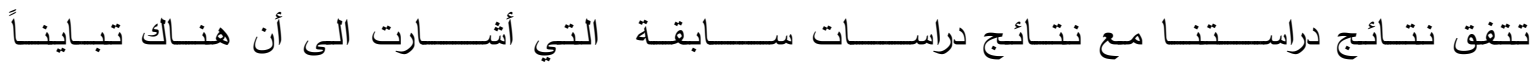

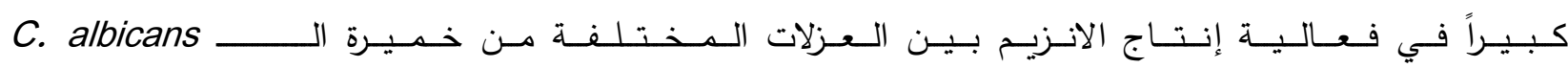
ففي دراسة اجراها Borst و Fluit (29) على 186 عزلة من الـــ albicans والمعزولة من مصـادر مختلفة (الدم والقناة التتفسية والقناة البولية والجروح) والتي اظهرت ان 72\% من مجموع العزلات كانت منتجة للانزيم وبنسب متفاوتة وحسب موقع الإصــابة فقد كانت 87\% من عزلات القناة التتفــية و 72\% من عزلات القناة البولية و 71\% من الدم و 29\% من عزلات

· الجروح

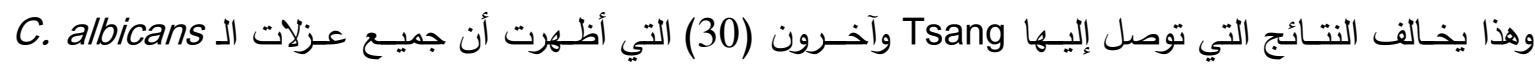
والبالغ عددها 76 عزلة والمعزولة من فم المرضسـى المصــابين بداء السـكري كانت منتجة للانزيم وقد تراوحت قيم Pz لها من 0.89 الى 0.68

وفي دراسة أجراها Sachin وآخرون (31)على انواع من الــCandida والمعزولة من مصادر مختلفة (الدم ومسحات فموية ومســـحات مهبلية وادرار) والتي أظهرت أن 36 عزلة من مجموع 39 عزلة أي بنســبة 92.3\% كانت منتجة لانزيم 
الفوسـفولايبيز ، وكانت هذه النسبة عالية بالمقارنة مع نسـب العزلات الموجبة للأنواع الأخرى من الـــCandida التي شـلتها الدراسـة، إن هذا الاختلاف في نسـب العزلات الموجبة لكل دراسـة ربما يعتمد على عدة عوامل منها مواصـفات العزلة نفسـها وموقع الاصابة ، كما أن الجين المسؤول عن تثفير هذا الانزيم يتأثر بظروف النمو، وربما قد يكون لعدد العزلات المدروسة في كل دراسة تاثير (بشكل جزئي) على التباين في نتائج الدراسات المختلفة (30).

\section{5- فعالية عزلات الـ C. albicans في انتاج الهيمولايسين}

أظهرت نتائج هذا الأختبار أن جميع عزلات الـ C. albicans في دراستتا الحالية (100\%) كانت منتجة للهيمولايسين إذ أظهرت فعالية في تحليل الدم ، وكانت هذه الفعالية من نوع بيتا ، إذ تم ملاحظة التحلل الكامل للدم والذي ظهر بشكل منطقة نصف شفافة حول المستعمرات النامية على وسط سـابرود دكستروز الصـلب الحاوي على دم الاغنام والغني بسكر الكلوكوز بتركيز 3\% ومن خلال الجدول (3) نلاحظ أن هناك اختلافاً في قدرة عزلات الــ C. albicans على إنتاج الهيمولايسين ، إذ ترواحت قيم دلائل التحليل (Hi) لهذا العامل من 1.48 الى 2.16 ومعظم العزلات ذات فعالية في إنتاج هذا العامل ، ومن خلال إجراء التحليل الاحصـائي باختبار دنكن المتعدد المدى عند مسـتوى احتمال 1\% لاحظنا أن هناك فروقاً معنوية بين قيم دلائل التحليل للعزلات، إذ إخذت العزلة RA7 الحرف a و تفوفت على جميع العزلات وقد بلغت قيمة الإنتاج 2.16 والتي لم تختلف معنويا عن العزلتين

RA19 و RA10 إذ كانت قيم إنتاجهما لهذا العامل 2.00 لكل منهما ثم تدرجت بقية العزلات في قيم دلائل تحليلها انخفاضاً الى أن وصلت 1.48 للعزلة RA31 والتي أظهرت أدنى فعالية في انتاج الهيمولايسين .

إن نتائج دراسـتـا الحالية جاءت متفقة مع دراسـات اخرى كالدراســة التي قامت بها Sرeker (32) على 207 عزلة

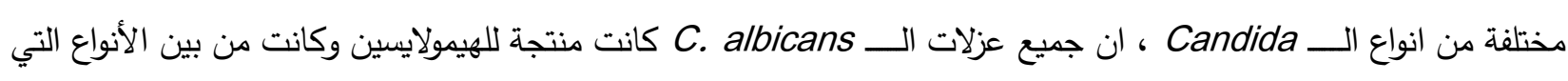

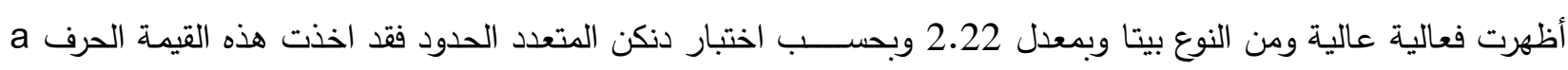

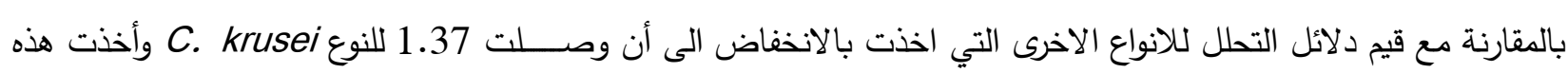
القيمة احصائيا الحرف d في حين كانت جميع عزلات النوع C. parapsilosis في هذه الدراسة سالبة لهذا الاختبار . في حين أظهرت نتائج دراسة حديثة قام بها Sachin وآخرون (31) على انواع مختلفة من الـ Candida والمعزولة من مصادر مختلفة (دم و ادرار ومسحات فموية ومسحات مهبلية) ومن بينها 39 عزلة من الـ C. albicans ،كانت فقط 37 عزلة منتجة للهيمولايسين أي بنسبة 94.8\% في حين أظهرت عزلتان نتيجة سالبة لهذا الاختبار . 
إن قدرة العزلات على انتاج الهيمولايسين تختلف باختلاف أنواع الــ Candida وكذلك تختلف ضمن افراد النوع الواحد وذلك اعتمادا على مصـادر العزل (33) ، كما يجب أن نضـع بنظر الاعتبار انه ربما هناك انواع من الهيمولايسين خاصـة بكل نوع نو

ان المعلومات المتوفرة عن عامل الضراوة الهممولايسين مازالت قليلة ، وهناك حاجة الى المزيد من الدراسات من اجل الكثـف عن طبيعة هذا العامل المحلل للدم Hemolytic factor في الـــ albicans وعن فائدته في التشـخيص والكثف بثــكل رئيس عن تاثيره على خلايا العائل ، وقد يثــبه هذا العامل الانزيمات خارج خلوية ، وبذلك يســاعد في تمييز العزلات (13). كما أن الدراسات حول انتاج الهيمولايسين من قبل عزلات الـــCandida والمعزولة من الفم مازالت محدودة ، وإن أول دراســة أجريت حول فعالية تحليل الدم لعزلات من الــــ C. albicans والمعزولة من التجويف الفموي كانت من قبل Tsang

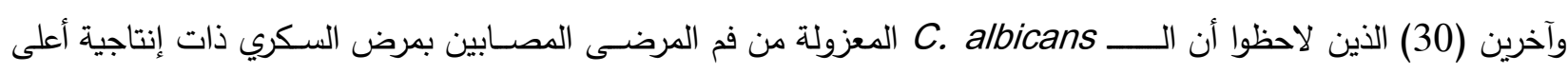

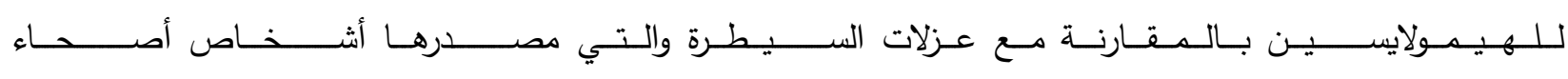

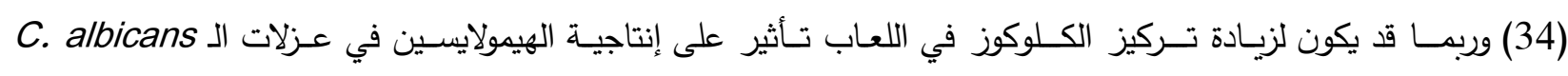
(30) ، وهذا ما أكده Manns وآخرون (21) في دراستهم التي لاحظوا فيها عدم وجود فعالية إنتاج الهيمولايسين في عزلات الـ C. albicans إن العامل المحلل للدم هو أحد عوامل الضراوة في أنواع الـ Candida والذي يسهم في إمراضية الـ Candida ولأهميته فهو يتطلب دراسات جديدة وأكثر جدية (13). 
الجدول (3) : فعالية عزلات الـ C. albicans في انتاج انزيم الفوسفولايبيز و الهيمولايسين

\begin{tabular}{|c|c|c|}
\hline He معدل قيم & معدل قيم Pz & رمز العزلة \\
\hline *bcd 1.88 & $\begin{array}{ll}\text { i } & \mathbf{0 . 0 0} \\
\end{array}$ & RA1 \\
\hline b-e 1.83 & fgh 0.56 & RA4 \\
\hline b-g $\quad 1.74$ & efg 0.63 & RA5 \\
\hline $\begin{array}{ll}-g & 1.66 \\
\end{array}$ & b-e 0.69 & RA6 \\
\hline 2.16 & cde 0.67 & RA7 \\
\hline 1.55 & a-e 0.72 & RA8 \\
\hline abc 1.93 & a-d 0.73 & RA9 \\
\hline $\begin{array}{ll}\text { ab } & 2.00 \\
\end{array}$ & $\begin{array}{ll}\text { i } & 0.00 \\
\end{array}$ & RA10 \\
\hline 1.71 & gh 0.54 & RA11 \\
\hline b-f $\quad 1.76$ & i $\quad 0.00$ & RA12 \\
\hline bcd 1.88 & h $\quad 0.53$ & RA13 \\
\hline bcd 1.88 & \begin{tabular}{cc|} 
i & 0.00 \\
\end{tabular} & RA14 \\
\hline 1.56 & a-e 0.72 & RA16 \\
\hline d-g 1.64 & abc $\quad 0.76$ & RA17 \\
\hline 2.00 & $\begin{array}{ll}\text { a } & \mathbf{0 . 8 0} \\
\end{array}$ & RA19 \\
\hline 1.76 & $\begin{array}{ll}\text { ab } & 0.78 \\
\end{array}$ & RA21 \\
\hline 1.83 & abc 0.77 & RA22 \\
\hline 1.83 & $\begin{array}{ll}\text { a-e } & 0.72\end{array}$ & RA23 \\
\hline 1.77 & def 0.65 & RA24 \\
\hline 1.81 & b-e $\quad 0.69$ & RA25 \\
\hline 1.59 & cde 0.67 & RA26 \\
\hline 1.49 & abc 0.77 & RA27 \\
\hline 1.63 & a-d 0.73 & RA29 \\
\hline 1.81 & abc 0.77 & RA30 \\
\hline 1.48 & abc 0.76 & RA31 \\
\hline 1.57 & $\begin{array}{ll}\text { i } & \mathbf{0 . 0 0} \\
\end{array}$ & RA32 \\
\hline 1.64 & cde 0.67 & RA33 \\
\hline 1.59 & $\begin{array}{ll}\text { i } & 0.00 \\
\end{array}$ & RA34 \\
\hline $\begin{array}{ll}\text { b-g } & 1.74 \\
\end{array}$ & $\begin{array}{ll}\text { a-d } & 0.74 \\
\end{array}$ & RA36 \\
\hline
\end{tabular}

*الالمعدلات ذات الاحرف المتثابهة لا تختلف معنويا عند مستوى احتمال 1\% بحسب اختبار دنكن المتعدد المدى.

1. Barnett, J. A., Yeast, 25: 385-417, (2008).

2. Kumar, M. A. and Rajsekhar, S., Inter. J. Res., Ayurveda Pharm., 2(6): 1722-1725, (2011).

3. Shibata, T. ; Yamashita, D. ; Hasegawa, S. ; Saito, M. ; Otsuki, N. ; Hashikawa, K. ; Tahara, S. and Nibu, K., Auris Nasus Larynx, 38: 418-420, (2011).

4. Dangi, Y. S. ; Soni, M. L. and Namdeo, K. P. , Int. J. Pharm. Pharm. Sci., 2(4): 36-41, (2010).

5. Pires-Gonçalves, R. H. ; Miranda, E. T. ; Baeza, L. C. ; Matsumoto, M. T. ; Zaia, J. E. and Mendes-Giannini, M. J. S. , Mycopathologia, 164: 255-263, (2007). 
6. Tarçin, B. G. , J. Mar. Uni. Inst. Health Sci., 1(2): 140-148, (2011).

7. Ge, Y. P. ; Lu, G. X. ; Shen, Y. N. and Liu, W. D. , Mycopathologia, 172:429-438, (2011).

8. Ghannoum, M. A. , Clin. Microbiol. Rev.,13(1):22-143, (2000).

9. Yang, Y. , J. Microbiol. Immunol. Infect., 36:223-228, (2003).

10. Abu-Elteen, K. H. ; Elkarmi, A. Z. and Hamad, M. A., Jpn. J. Infect. Dis., 54: 229-236, (2001).

11. Sardi, J. C. O. ; Duque, C. ; Mariano, F. S. ; Peixoto, I. T. A. ; Höfling, J. F. and Gonçalves, R. B. , J. Oral Sci., 52(2): 177-185, (2010).

12. Silva, S. ; Negri, M. ; Henriques, M. ; Oliveira, R. ; Williams, D. W. and Azeredo, J., FEMS Microbiol. Rev., 36: 288-305, (2012).

13. Yigit, N. and Aktas, E. , J. Med. Mycol., 19: 110-115, (2009).

14. Santos, R. ; Buisson, N. ; Knight, S. ; Dancis, A. ; Camadro, J. and Lesuisse, E. , Microbiology, 149: 579-588, (2003).

15. Furlaneto-Maia, L. ; Specian, A. F. ; Bizerra, F. C. ; de Oliveira, M. T. and Furlaneto, M. C., Mycopathologia, 166: 209-217, (2008).

16. Chaffin, W. L. ; López-ribot, J. L. ; Casanova, M. ; Gosalbo, D. and Martinez, J. P. , Microbiol. Mol. Biol. Rev., 62(1):130-180, (1998).

17. Price, M. F. ; Wilkinson, I. D. and Gentry, L. O. , Sabouraudia, 20: 7-14, (1982).

18. Luo, G. ; Samaranayake, L. P. and Yau, J. Y. Y. , J. Clin. Microbiol., 39(8): 2971-2974, (2001).

19. Aubertine, C. L. ; Rivera, M. ; Rohan, S. M. and Larone, D. H. , J. Clin. Microbiol., 44(1): 227-228, (2006).

20. Valenza, G. ; Strasen, J. ; Schäfer, F. ; Frosch, M. ; Kurzai, O. and Abele-Horn, M. , J. Clin. Microbiol., 46(11): 3784-3787, (2008).

21. Manns, J. M. ; Mosser, D. M. and Buckley, H. R. , Infect. Immun., 62(11): 5154-5156, (1994).

22. Favero, D. ; França, E. J. G. ; Furlaneto-Maia, L. ; Quesada, R. M. B. and Furlaneto, M. C. , Mycoses, 54(6): 816-820, (2011).

23. Kurtzman, C. P. and Fell, J. W. , The Yeasts, A Taxonomic Study. $4^{\text {th }}$ ed., Elsevier Science B.V., The Netherland, (1998).

24. Raju, S. B. and Rajappa, S. , Int. Scholarly Res. Network, 2011: 1-7, (2011).

25. Agarwal, S. ; Manchanda, V., Verma, N. and Bhalla, P. , Ind. J. Med. Microbiol.,29(2): 172177, (2011).

26. Meletiadis, J. ; Arabatzis, M. ; Bompola, M. ; Tsiveriotis, K. ; Hini, S. ; Petinaki, E. ; Velegraki, A. and Zerva, L. J. Clin. Microbiol., 49(7): 2722-2727, (2011). 
27. Mardegan, R. ; Klein, M.I. ; Golvea, M. B. ; Rodrigues, J. A. O. ; Gonçalves, R. B. and Höfling, J. F. , Braz. J. Microbiol., 37: 26-32, (2006).

28. Niewerth, M. and Korting, H. C. ,Mycoses, 44:361-367, (2001).

29. Borst, A. and Fluit, Ad. C. , J. Med. Microbiol., 52:971-974, (2003).

30. Tsang, C. S. P. ; Chu, F. C. S. ; Leung, W. K. ; Jin, L. J. ; Samaranayake, L. P. and Siu, S. C. , J. Med. Microbiol., 56: 1393-1398, (2007).

31. Sachin, C. D. ; Ruchi, K. and Santosh, S. , Intr. J. Med. Biomed. Res., 1(2): 153-157, (2012).

32. Şeker, E. , Mycopathologia, 169: 303-308, (2010).

33. Shehabi, A. A. ; Nazzal, S. A. and Dajani, N., Microb. Ecol. Health Dis., 16: 214-216 , (2004).

34. Yigit, N. ; Aktas, E. ; Dagistan, S. and Ayyildiz, A., Eura. J. Med., 43: 27-32, (2011). 